\title{
Creencias docentes: El enfoque de género en la educación y la educación sexual en secundaria
}

\author{
Andrea Lucía Rodríguez Reyes \\ Grupo de Investigación Psicología, Cultura y Género \\ Pontificia Universidad Católica del Perú \\ rodriguez.andrea@pucp.pe \\ María Angélica Pease \\ Grupo de Investigación Psicología, Cultura y Género \\ Pontificia Universidad Católica del Perú \\ mapease@pucp.edu.pe
}

Recibido: $15 / 04 / 2019$

Aprobado: 23/06/2020 


\section{Creencias docentes: El enfoque de género en la educación y la educación sexual en secundaria}

\section{Resumen}

Esta investigación tuvo como finalidad explorar las creencias docentes sobre el enfoque de género en la educación y la educación sexual de un grupo de docentes de secundaria de una institución educativa pública de la provincia de Cañete. Para ello, se aplicó una entrevista a profundidad a seis docentes - tres hombres y tres mujeres-, distribuida en dos áreas de creencias docentes: una sobre educación sexual y otra sobre el enfoque de género en la educación. Los resultados muestran tres creencias docentes predominantes conservadoras en relación con la sexualidad, el sexo y el género, que influyen en cómo entienden la educación sexual y el enfoque de género: la sexualidad es principalmente biológica, sexo y género son lo mismo, y la homosexualidad es anormal. Estas creencias promueven la reproducción de modelos de riesgo y moralistas para abordar la educación sexual y una visión negativa sobre el enfoque de género en la educación. De acuerdo con las creencias de este grupo de docentes, dicho enfoque buscaría "homosexualizar" a sus estudiantes, a pesar de que lo planteado en las entrevistas muestra un discurso de equidad entre hombres y mujeres, desde el cual el enfoque de género sería adecuado. Así, existe un enfoque inclusivo binario que funciona, pero las identidades de género son más difíciles de asumir. El estudio, también, ha identificado tres creencias docentes diferentes a las predominantes, desde un enfoque más integral: el respeto a personas con orientación sexual distinta a la heterosexual, la necesidad de hablar sobre educación sexual en el aula, y la importancia de la igualdad de oportunidades para hombres y mujeres.

Palabras clave: Creencias docentes, género, sexualidad, educación sexual, enfoque de género 


\title{
Teachers' beliefs: Gender approach in education and sexual education in high school
}

\begin{abstract}
The present study aimed to explore teachers' beliefs about gender approach in education and sex education in a group of high school teachers from a public school in the province of Cañete. Six teachers were interviewed, three men and three women, distributed in two specific areas about teachers' beliefs: one for gender approach in education and another one for sex education. Results show three prevalent conservative teachers' beliefs about sexuality, sex and gender, that influence on how they understand sex education and gender approach: sexuality as mainly biological, sex and gender as the same, and homosexuality as abnormal. These beliefs promote the reproduction of risk and moralist models to address sexual education and a negative view of the gender approach in education, because they believe that it seeks to "homosexualize" their students. Despite these beliefs, these teachers express a discourse that supports equity between men and women, which is aligned with a gender approach. Therefore, even though an inclusive binary approach works, there are still difficulties to accept diversity in terms of gender identities. The study has also noted the presence of three different teachers' beliefs from a more comprehensive approach: respect towards people with a sexual orientation other than heterosexual, the need to talk about sex education in classroom, and the relevance of the equal opportunities between men and women.
\end{abstract}

Keywords: Teachers' beliefs, gender, sexuality, sexual education, gender 


\section{Introducción}

A inicios del 2019, el Estado peruano tomó la iniciativa histórica de aprobar la Política Nacional de Igualdad de Género (Ministerio de la Mujer y Poblaciones Vulnerables [MIMP], 2019), medida que dialoga con el Enfoque de Igualdad de Género propuesto en el Currículo Nacional del Ministerio de Educación (Minedu, 2016). Sin embargo, ambas propuestas se aprobaron en medio de un clima de controversia propiciado principalmente por colectivos ultraconservadores provenientes de la Iglesia católica e iglesias evangélicas. Esta situación la atraviesa gran parte de Latinoamérica, donde se ha gestado un fuerte movimiento contra la educación sexual integral y el enfoque de género, este último denominado "ideología de género" (Motta et al., 2017).

En Perú, esta oposición ha sido liderada por los colectivos Con Mis Hijos No Te Metas (CMHNTM) y Padres en Acción Perú (PEA). A raíz de la aprobación del actual Currículo Nacional, gestionaron una campaña de desprestigio a las propuestas ya referidas. De acuerdo con estos colectivos, la "ideología de género" promueve orientaciones no heterosexuales e identidades transgénero (Motta et al., 2017), así como el inicio temprano de relaciones sexuales (CMHNTM Perú-Oficial, 2016). La influencia política de estos colectivos ultraconservadores y la demanda interpuesta por PEA (2017) derivaron en que el Minedu se viera forzado a eliminar toda referencia a este enfoque durante el 2018. Esta condición cambió en el 2019, cuando la Corte Suprema declaró infundada la demanda (Corte Suprema de Justicia de la República, 2019).

Estudios sobre la implementación del enfoque de género y la educación sexual en Perú evidencian el escaso acompañamiento docente sobre estas temáticas, la persistencia de un currículo oculto que contradice los postulados del Minedu y la reproducción de estereotipos de género por parte de la plana docente en las aulas (Dirección de Tutoría y Orientación Educativa [Ditoe], y Organización de las Naciones Unidas para la Educación, la Ciencia y la Cultura [Unesco] 2013; Motta et al., 2017). Ello resulta preocupante al considerar las alarmantes cifras de salud sexual adolescente en Perú, que resaltan la existencia de barreras para que las y los adolescentes lleven una vida sexual y reproductiva saludable (Motta et al., 2017). Los indicadores del Instituto Nacional de Estadística e Informática (INEI, 2015) evidencian una tasa relativamente baja en el uso de métodos anticonceptivos entre las adolescentes y un bajo conocimiento integral del VIH/sida. Además, se identifican desigualdades regionales con respecto al inicio de la actividad sexual y de la maternidad (Motta et al., 2017), marco en que las adolescentes en mayores condiciones de pobreza son más propensas a quedar embarazadas (Rodríguez, 2014).

La problemática descrita ilustra el desafío que supone la implementación de políticas educativas sobre género y sexualidad: el hecho de que, a pesar del respaldo legal, persiste el reto de conciliar enfoques integrales con enfoques más conservadores (Motta et al., 2017). Asimismo, esta situación revela el rol 156 I protagónico de la plana docente en los procesos de enseñanza-aprendizaje 
(Plaza, 2015), en los que se encuentran contenidas transversalmente las temáticas de género y sexualidad.

En este panorama, el estudio de las creencias docentes ayuda a comprender las complejidades de la implementación del enfoque de género y la educación sexual, dado que influyen en el desarrollo de la práctica pedagógica (Calderhead, 1996). Además, en tanto las creencias son estructuras mentales que se emplean para entender de forma personal la realidad educativa - desde cómo aprenden hasta cómo enseñan-, pueden limitar la influencia de aquellos nuevos conocimientos explícitos en su práctica pedagógica si es que estos no se encuentran en concordancia con las creencias docentes más profundas (Catalán, 2011).

Pese a su importancia, no contamos con numerosos estudios que abordan las creencias docentes sobre la educación sexual y el enfoque de género (Meinardi, Plaza y Revel Chion, 2010), aun cuando el estudio de creencias docentes ha cobrado creciente interés en la psicología de la educación. Los estudios de problemáticas de género en la escuela desde la psicología educacional tampoco abundan en nuestro país, por lo que resulta particularmente importante poder contribuir a la comprensión de estas temáticas desde esta perspectiva teórica.

\section{El enfoque de género en la educación y la educación sexual}

Una educación con enfoque de género está orientada a promover y asegurar el acceso igualitario de todas las personas a las oportunidades educativas, de modo que se garanticen espacios educativos donde hombres y mujeres reciban un trato justo y equitativo en los procesos de enseñanza-aprendizaje, en lucha frontal contra la discriminación por género y los estereotipos de género. Es, además, una educación que reconoce la diversidad de los distintos grupos de personas con orientación sexual o de género diferentes a las heteronormadas (Unesco, 2015).

Esta declaración de intenciones educativas concibe al género desde un enfoque integral que tiene principalmente dos dimensiones. La primera concibe al género como un conjunto de normas y prescripciones construidas por la sociedad y la cultura sobre lo que es ser hombre y mujer, a partir de las diferencias biológicas de las personas, lo cual rompe con la perspectiva biologicista y binaria del género (Lamas, 2009). Entiende, además, que estas construcciones culturales han estructurado un sistema de relaciones de género. Dicho sistema funge como contenedor de expectativas y valores que dictaminan las reglas de cómo hombres y mujeres deben actuar en el plano personal e interpersonal, en el que las mujeres han sido posicionadas en un nivel jerárquico inferior en relación con los hombres (Morgade, 2001).

La segunda dimensión concibe al género como un importante componente de la identidad de las personas, dado que configura la construcción de la propia identidad de género, la cual refiere al sentimiento interno de saberse hombre, mujer o incluso algo fuera de estas categorías. Así también, tiene 
vínculo con la expresión de género, entendida como la manera en que la persona expresa su identidad de género a través de su comportamiento, modo de vestir, peinar, o caracterizar al cuerpo (Asociación de Psicología Americana, APA, 2011).

Por su lado, desde un enfoque integral, la educación sexual debe orientarse a dotar a las y los estudiantes de competencias para la toma de decisiones informadas que promuevan la capacidad de responder de forma asertiva a los cambios físicos y emocionales propios de su desarrollo sexual e integral. Asimismo, debe brindar espacios confiables y seguros donde puedan desarrollarse como personas y como seres sexuales sin temores ni prejuicios, de tal manera que sientan seguridad y confianza. En este sentido, un enfoque integral debe materializarse en un proceso de enseñanza-aprendizaje que contribuya a la ética, la igualdad de género y a los derechos humanos (Unesco, 2014).

Desde este enfoque, la sexualidad es concebida como un sistema complejo que no solo abarca una dimensión intrapersonal, sino que también implica una dimensión interpersonal (Vásquez, 2015). Asimismo, se pone de relieve su rol fundamental en la conformación de la identidad de las personas, al ser un proceso desarrollado a lo largo del ciclo vital (Abenoza, 1994). Se entiende, entonces, que el desarrollo de la identidad sexual engloba la autoconciencia de pertenecer a un determinado sexo-la vivencia interna y/o personal de sentirse masculino, femenina, o fuera de estas categorías (identidad de género) - y también la atracción afectiva, erótica y sexual que experimenta la persona en su interior en función de su sentir con las otras personas (orientación sexual) (Bardi, Leyton, Martínez y Gonzáles, 2005).

Sin embargo, el concepto de sexualidad ha tenido y tiene múltiples significados según el contexto sociocultural y la perspectiva con la que se aborda (Plaza, 2015). Existen enfoques diversos que pueden partir desde lo más tradicional que la restringe al acto sexual- hasta enfoques más integrales, como los descritos anteriormente (Aller, 1995). Esta diversidad en las actitudes y creencias sobre la sexualidad supone aún la mediación de enfoques más tradicionales al momento de abordar este constructo y, por ende, la educación sexual. Al respecto, según la Asociación Española de Especialistas en Sexología (AESS) et al., (2012) existen tres modelos que agrupan los programas implementados a la fecha en materia de educación sexual: el de riesgos, el moral y el integrador.

Según el Fondo de Poblaciones para las Naciones Unidas (Unfpa, 2005), el modelo de riesgos agrupa principalmente programas orientados a regular las tasas de natalidad; en ese sentido, se relaciona con una visión biológica de la sexualidad que resalta la transmisión de posibles enfermedades y las consecuencias negativas del acto coital (Vásquez, 2015). El modelo moral se orienta a fomentar la abstinencia como único método seguro (AESS et al., 2012). Además, considera que el sexo es un tema prohibido dentro de los planes curriculares educativos (Plaza, 2015). Esta lógica se vincula con visiones moralistas de la sexualidad, que tienen una gran influencia de la religión judeocristiana 158 I (Vásquez, 2015). 
Ambos modelos han mostrado ser poco eficaces para mejorar los indicadores de salud sexual y reproductiva (Underhill, Montgomery y Operario, 2007; Kirby, 2008), mientras que los programas adscritos al modelo integrador han reflejado resultados positivos para las y los adolescentes. Estos programas reconocen la actividad sexual como un hecho real y esperable durante la adolescencia, y conciben la salud sexual como un elemento indispensable para el bienestar personal y la calidad de vida de las personas (AEES et al., 2012). Han evidenciado efectividad para potenciar habilidades en la toma de decisiones de adolescentes, cambiar actitudes, y normas sociales y de género negativas; asimismo, han aumentado el empleo de preservativos masculinos y diversos métodos de anticoncepción (Motta et al., 2017).

\section{El enfoque de género en la educación y la educación sexual en el Perú}

La propuesta del Minedu se adhiere a los lineamientos orientados a promover y garantizar una educación con enfoque de género y programas de educación sexual integral, como se mencionó con anterioridad. Ello constituye un avance importante en lo que respecta a situaciones previas, en que no existía una normativa nacional con rango de ley que respaldara ambas propuestas (Motta et al., 2017; Rodríguez, 2018).

El enfoque de género se incorpora al sistema educativo desde el Diseño Curricular Nacional 2005 y pasó a ser definido como estrategia transversal en el Currículo Nacional 2016 bajo la denominación de Enfoque de Igualdad de Género. De acuerdo con este, "Todas las personas, independientemente de su identidad de género, tienen el mismo potencial para aprender y desarrollarse plenamente. La Igualdad de Género se refiere a la igual valoración de los diferentes comportamientos, aspiraciones y necesidades de mujeres y varones" (Minedu, 2016, p. 16).

En cuanto a la educación sexual, el Minedu en sus inicios se rigió bajo un enfoque biológico-reproductivo, destinado a controlar las tasas demográficas desde los años 60 con programas dirigidos principalmente a mujeres. Hacia finales del siglo pasado, este enfoque perdió validez con la firma de diversos tratados internacionales, en los que el Perú se comprometió a promover gradualmente un enfoque integral (Motta et al., 2017). A partir de ello, el Minedu publicó los Lineamientos para una Educación Sexual Integral, documento en que señala que la educación sexual implica un proceso formativo mediante el cual cada estudiante se desarrolla como persona autónoma y responsable, con conocimientos, capacidades, actitudes y valores que posibilitan el ejercicio de su derecho a una sexualidad integral (Ditoe, 2008).

La proposición de una educación con enfoque de género y una educación sexual integral, además de requerir un respaldo legal sólido para su implementación eficaz (Rodríguez, 2018), también demanda con urgencia la tarea formativa de docentes para desarrollar acciones pedagógicas y de orientación bajo un enfoque de género. Dichas acciones posibilitarían la adquisición de 
capacidades y actitudes necesarias para la expresión de una sexualidad sana, responsable y placentera de los estudiantes (Ditoe, 2008). No obstante, investigaciones recientes sobre el estado de la educación sexual en el Perú señalan que la mayoría de docentes no se sienten en la capacidad de trabajar temas de sexualidad con sus estudiantes, reportan escaso acompañamiento por parte del Estado y consideran que no tienen las herramientas metodológicas necesarias para abordarla en el aula (Minedu, 2006 citado en Ditoe, 2013; Motta et al., 2017). Adicionalmente, las y los docentes tienen creencias, prejuicios e inseguridades sobre su propia sexualidad que dificultan su labor en relación con la educación sexual, y establecen diferencias considerables en la significación de la sexualidad de hombres y mujeres (Minedu, 2006, citado en Ditoe, 2013). Los mensajes transmitidos por la plana docente al abordar temas de educación sexual evidencian la persistencia de contenidos relacionados con una visión restrictiva de la sexualidad. Desde esta visión, las relaciones sexuales se restringen al ámbito matrimonial, y, en general, son percibidas como inmorales y peligrosas. A su vez, mantiene la idea de que la homosexualidad es antinatural (Motta et al., 2017).

Ante el panorama descrito, consideramos conveniente explorar las creencias docentes en lo que respecta a la educación sexual y al enfoque de género en la educación como un medio para analizar e identificar aquellas que posibilitan y dificultan la implementación de los lineamientos del Minedu.

\section{Creencias docentes}

Las creencias docentes son estructuras mentales que se emplean para entender de forma personal la realidad educativa, desde cómo se aprende hasta cómo se enseña (Pajares, 1992) e influyen en el accionar pedagógico docente (Moreno, 2005). Se trata de proposiciones subjetivas generadas individualmente para comprender (Pajares, 1992), explicar, y justificar decisiones y accionares personales y profesionales (Moreno, 2001). Dichas proposiciones actúan como filtros que afectan cómo se percibe y se acepta la información del entorno, y cómo se guarda, recupera y utiliza el conocimiento (Marcelo, 2005; Catalán, 2011).

La formación de creencias sucede desde una edad muy temprana a través del proceso de socialización en una cultura determinada. Según Vygotsky (2000 [1978]), este es el proceso por el cual la mente internaliza la cultura mediante lo que él denominó "la ley de doble formación intra-interpsicológica". Así, enfatiza la idea de que todo aquello que configura la mente se aprende, en primera instancia, en la relación con el entorno sociocultural, lo cual explica el hecho de que naturalicemos mucha de la información cultural aprendida a edades tempranas. Ahora bien, las creencias se articulan en sistemas que tienden a perpetuarse en el tiempo y suelen tomarse como verdades indiscutibles. Más aún, se tiende a superar las contradicciones entre una creencia e informa-

160 I ción disonante, obviando aquella información que no forme parte del sistema 
de creencias constituido (Pajares, 1992).

En contraste con el conocimiento, basado principalmente en hechos objetivos, las creencias no se fundamentan sobre la racionalidad, sino sobre los sentimientos, experiencias y ausencias de conocimientos específicos sobre el tema al que refieren (Moreno, 2001). Organizadas bajo un parámetro no lógico, es posible el mantenimiento de creencias y concepciones contradictorias sin que medie un conflicto (Callejo y Vila, 2003; Pajares, 1992). En tal sentido, se asocian con una alta carga emocional impregnada de compromisos afectivos que guían el pensamiento y la acción (Borg, 2001), y no llegan a ser explícitas con facilidad (Marcelo, 1987). Por ello, múltiples autores - Bandura, 1986; Ernst, 1989; Dewey, 1933; Nespor, 1987; Nisbett y Ross, 1980; Rokeach, 1968, citados en Pajares, 1992- destacan la importancia del efecto de las creencias docentes para entender y predecir su práctica dentro del aula.

Además, se ha identificado que, si las creencias docentes más profundas no se encuentran en concordancia con los conocimientos explícitos, adquiridos posteriormente, las mismas pueden sustituirlos (Catalán, 2011). Ello podría explicar por qué en múltiples oportunidades las y los docentes no siguen las directrices institucionales del currículum nacional propuesto por los ministerios de sus respectivos países, a pesar de mencionar su intención por aplicarlas (Plaza, 2015). En esa medida, se podría inferir que, aunque se adopte un enfoque de género en el marco de la educación de un país, no se asegura que se aplique. Más bien, dependerá del nivel de concordancia con que los postulados teóricos de la propuesta se alineen con las creencias profundas de la plana docente. Frente a esta situación, es relevante el estudio de las creencias docentes sobre estas temáticas, en tanto se constituye como un medio para enfrentar la problemática que supone la persistencia de un currículo oculto (Bank, 2007). Con este término, nos referimos a aquel currículo que se guía principalmente por las creencias y valores personales - estereotipados y heteronormadosque tiene cada docente sobre la sexualidad y el género (Plaza, 2015).

\section{Creencias docentes sobre el género y la sexualidad}

A pesar de lo problemático de la realidad descrita, existen pocos estudios que aborden las complejidades del enfoque de género en la educación y de la educación sexual desde el estudio de las creencias docentes. Las investigaciones se han orientado al estudio de estas creencias en relación con el rendimiento escolar y la caracterización de sus estudiantes en función de su sexo, así como en su influencia en la interacción de la plana docente con sus estudiantes en clase ${ }^{1}$.

Con respecto al estudio de las creencias docentes sobre sexualidad y la educación sexual, algunos trabajos se han centrado en las formas cómo las y los docentes han definido estos constructos. Una investigación cualitativa estadounidense dirigida a docentes de secundaria señaló que, aunque se ma-

1. Para esta discusión, se puede consultar Meinardi, Plaza y Revel Chion (2010). 
neja un concepto holístico de la sexualidad, persiste una visión de riesgo de la misma (Preston, 2013). En España, Díaz de Greñu y Anguita (2017) llevaron a cabo una investigación cualitativa con docentes de secundaria y bachillerato, e identificaron una visión restringida de la sexualidad que reproduce estereotipos referidos al género y a la orientación sexual.

En Latinoamérica, el estudio en escuelas públicas de Brasil, realizado por Quaresma da Silva (2012), identificó creencias docentes sobre género y sexualidad que movilizan representaciones hegemónicas de masculinidades y feminidades, y reproducen situaciones de discriminación, marginación y exclusión entre los géneros y al interior de los mismos. El estudio concluye, de forma general, que se desempeña un rol fallido para la consecución de una educación sexual como enfoque transversal, pues esta se limita a un espacio de prácticas correctivas y regulatorias desde una lógica heteronormada. Plaza (2015), por su parte, realizó un estudio cualitativo con docentes de una escuela secundaria estatal en Argentina. La autora encontró que existen creencias generalmente estereotipadas y heteronormadas sobre la sexualidad y el género, que reflejan la preponderancia del rol masculino ante el femenino (Plaza, 2015).

La evidencia indica que las diferencias de género aún se reproducen dentro de las experiencias educacionales de estudiantes; en la mayoría de ellas, están implicados sus docentes (Garrahay, 2001). Además, persisten visiones restrictivas con respecto a la sexualidad, que se materializan en discursos y prácticas pedagógicas. Así, la introducción de las temáticas de sexualidad y género en las aulas pareciera quedar librada desde la voluntad de cada docente, basándose en sus propias creencias (Plaza, 2015). De esta manera, se desarrolla paralelamente a lo propuesto por el organismo público regulador de la educación.

En Perú, no existen investigaciones sobre las creencias docentes que se concentren en el enfoque de género en la educación ni en la educación sexual. Frente a este vacío en la literatura, es urgente y relevante realizar estudios sobre estas temáticas, sobre todo, considerando la propuesta educativa de este enfoque realizada por el Minedu a través del Currículo Nacional.

La presente investigación explora las creencias docentes sobre el enfoque de género en la educación y la educación sexual en docentes de nivel secundario en Perú, a través del desarrollo de un estudio cualitativo en el que participaron docentes de la provincia de Cañete de la ciudad de Lima. Se planteó como objetivo obtener alcances con respecto a los retos que enfrenta la implementación de una educación con enfoque de género y una educación sexual integral en nuestro país. Para tal fin, se plantearon los siguientes tres objetivos específicos: explorar las creencias docentes sobre (i) la sexualidad, el sexo y el género, (ii) la educación sexual, y (iii) el enfoque de género en la educación. 


\section{Método}

La investigación tuvo un abordaje cualitativo orientado a reconocer y analizar a profundidad los datos recogidos en los discursos docentes (González, 2007) con respecto al enfoque de género en la educación y la educación sexual, a través del reconocimiento de la experiencia propia y compartida de cada participante (Creswell, Hanson, Clark y Morales, 2007). Así, el estudio tuvo un enfoque fenomenológico (Husserl, 1998), como un medio para describir e interpretar la esencia de las experiencias vividas (Fuster, 2019) por el grupo de docentes participantes. En función del objetivo de general, se buscó entrevistar a docentes de escuela pública, se seleccionó una institución de forma intencional (Vieytes, 2004, por disponibilidad y facilidad de acceso. Se realizó entrevistas a profundidad a seis docentes, y la información fue estudiada mediante un análisis temático de tipo convencional (Hsieh y Shannon, 2005). Por su flexibilidad y dinamismo, este permitía ubicar ejes que brinden significación a partir de la información teórica existente (Hsieh y Shanon, 2005; Braun y Clarke, 2006).

\section{Participantes}

Se seleccionó una institución educativa (IE) pública, localizada en un área urbana costera de la provincia de Cañete, departamento de Lima. Dicha escuela solo imparte educación básica regular secundaria y agrupa a estudiantes provenientes de familias - en su mayoría - de un nivel socioeconómico bajo.

Seleccionamos seis docentes de esta IE de manera intencional (Vieytes, 2004), en función de los objetivos y características del estudio y el tipo de información que aportarían aspirando a criterios de diversidad. Se buscó que representaran diversos cursos, edades y distintos sexos. Solo se incluyó a docentes de secundaria que estén en actual ejercicio de la profesión docente y que hayan sido tutoras o tutores en los últimos tres años, en tanto el tema de la educación sexual suele ser abordado desde la tutoría.

El grupo de docentes laboraba en la IE durante el momento en que se llevaron a cabo las entrevistas. Estuvo constituido por 3 hombres y 3 mujeres, de edades que oscilaban entre los 34 y 50 años. Con respecto la formación inicial docente, la mayoría concluyó sus estudios en institutos pedagógicos (cuatro), y sus trayectorias como docentes en servicio fluctuaban entre los seis y veintiocho años. A continuación, se muestra una descripción más detallada. 
Tabla 1. Docentes según cursos que dictan, edad, años de servicio en general y en la IE, y tipo de formación docente recibida

\begin{tabular}{llcccc}
\hline Docente & \multicolumn{1}{c}{ Curso } & Edad & $\begin{array}{c}\text { Años de } \\
\text { servicio }\end{array}$ & $\begin{array}{c}\text { Años en } \\
\text { la IE }\end{array}$ & Formación \\
\hline Profesor 1 & Matemática & 50 & 24 & 24 & Universidad \\
Profesor 2 & Matemática & 50 & 25 & 23 & Instituto \\
Profesor 3 & Educación para el Trabajo & 40 & 8 & 2 & Instituto \\
Profesora 4 & Comunicación & 34 & 6 & 2 & Instituto \\
Profesora 5 & Cívica & 50 & 28 & 12 & Universidad \\
Profesora 6 & Religión & 46 & 20 & 6 & Instituto \\
\hline
\end{tabular}

Fuente: Elaboración propia.

Casi la totalidad de la muestra se describió como católica (5), con excepción del Profesor 2 (Matemática). Tres docentes reportaron haber recibido acompañamiento sobre educación sexual; no obstante, solo la Profesora 4 (Comunicación) la recibió desde un medio institucional del Minedu (Portal Perú Educa). En cuanto al acompañamiento en enfoque de género, solo una docente - la Profesora 6 (Religión) - reportó recibirla, pero, a través de una prelatura que forma parte del magisterio de la iglesia católica. En la siguiente tabla, se detalla esta información.

Tabla 2. Docentes según cursos que dictan, religión, acompañamiento en educación sexual (AES), y acompañamiento en enfoque de género (AEG)

\begin{tabular}{rlccc}
\hline Docente & \multicolumn{1}{c}{ Curso } & Religión & AES & AEG \\
\hline Profesor 1 & Matemática & Católica & Sí - Particular & No \\
Profesor 2 & Matemática & Cristiana & Sí - Particular & No \\
Profesor 3 & Educación para & Católica & Sí - Particular & No \\
& el Trabajo & & Sí - Minedu & No \\
Profesora 4 & Comunicación & Católica & No & No \\
Profesora 5 & Cívica & Católica & No & Sí- Prelatura \\
Profesora 6 & Religión & Católica & &
\end{tabular}

Fuente: Elaboración propia. 


\section{Instrumentos}

La información fue recogida mediante entrevistas semiestructuradas. Este instrumento incluía una ficha de datos demográficos que buscó describir a profundidad la muestra. Recogió datos como la edad, el sexo y género, religión, años de experiencia profesional en general y en la IE en la que laboran actualmente, cursos que enseñaban y si habían recibido algún tipo de acompañamiento sobre el enfoque de género en la educación y sobre la educación sexual por parte del Minedu o de manera particular.

En función de los objetivos específicos del estudio, las entrevistas exploraron las creencias docentes sobre (i) la sexualidad, el sexo y el género, (ii) la educación sexual, y (iii) el enfoque de género en la educación. Para controlar la potencial deseabilidad social con respecto al tema de investigación, se optó por desarrollar una guía de entrevista que incluyera casos, además de preguntas abiertas, por lo cual la entrevista se dividió en dos partes.

La primera parte se enfocó en seis casos específicos orientados a recoger información sobre las creencias docentes, a través del planteamiento de situaciones hipotéticas. Ante dichas situaciones, cada persona entrevistada debía posicionarse con la finalidad de ir más allá del conocimiento explícito docente. Esta estrategia suele usarse al abordar temáticas cargadas de emociones o con una elevada deseabilidad social, tal como se observa en el trabajo de Plaza (2015). Estos casos tuvieron como finalidad alcanzar los objetivos 2 y 3 de la presente investigación. A continuación, presentamos un ejemplo:

El profesor Luigi no quiere hablar de educación sexual en clase, porque cree que avivaría la curiosidad de sus estudiantes, y promovería que tengan relaciones sexuales a muy temprana edad. El profesor Ricardo, en cambio, considera que hablar de educación sexual en el aula les brindaría información útil a sus estudiantes y postergaría su inicio sexual.

Luego de la lectura de cada caso, se plantearon las siguientes preguntas: ¿Qué opina de la postura del docente X1? ¿Qué opina de la postura del docente X2? ¿Cuál postura se asemeja más a la suya? ¿Por qué?

En la segunda parte, se realizó trece preguntas abiertas divididas en dos áreas. La primera, sobre educación sexual, indagó en las ideas que el grupo de docentes tenía sobre la educación sexual en la escuela: su significado; su finalidad; y las estrategias empleadas, de ser el caso, para abordarla. Asimismo, profundizó en las creencias docentes sobre la sexualidad y el sexo. La segunda área comprendió preguntas abiertas sobre las ideas que las y los docentes tienen sobre el género y el enfoque de género en la educación: su significado; finalidad; y las estrategias empleadas, de ser el caso, para trabajar a partir de dicho enfoque. 


\section{Procedimiento}

En un primer momento, se elaboró una propuesta de guía de entrevista sobre la base de la revisión teórica del tema de investigación. Dicha propuesta fue revisada por cinco jueces: dos expertos en temas de género y sexualidad, dos en creencias docentes y uno en investigación cualitativa. A partir de la retroalimentación sobre la pertinencia de las preguntas, se realizaron los cambios pertinentes. Esta guía fue puesta a prueba en una entrevista piloto con una docente de la ciudad de Lima; el proceso no implicó cambios en su estructura.

En un segundo momento, se contactó con la dirección de la IE, y se informó acerca de los objetivos y características de la investigación para lograr su autorización. Luego de la aprobación, se procedió a invitar personalmente a las y los docentes. Se informó que su participación era voluntaria; que se respetaría el deseo personal de no participar; y que se mantendría el anonimato tanto de aquellas personas que participaran como de la IE.

En un tercer momento, luego de desarrollar las entrevistas, estas fueron transcritas y se realizó el análisis de la información recogida con el apoyo de una juez experta y del software Atlas.ti versión 7. Tras la primera codificación de la data, esta fue discutida con el apoyo y la supervisión de una juez experta. Después de ello, se volvió a repetir el proceso de codificación y se extrajeron tres categorías finales, que tomaron como referencia los objetivos planteados en la presente investigación, el marco teórico propuesto y los datos emergentes provenientes de los discursos docentes.

\section{Resultados y discusión}

Esta sección está organizada en función de las tres categorías centrales identificadas en el análisis de la información recogida: (i) creencias docentes sobre la sexualidad, el sexo y el género, (ii) creencias docentes sobre la educación sexual y las formas adecuadas de impartirla, y (iii) creencias docentes sobre el enfoque de género en la educación y lo propuesto por el Minedu.

En el reporte de este apartado, no se incluyeron las variables de edad, años de servicio, formación inicial docente ni religión, puesto que son muy pocos casos de estudio y el análisis de la información recogida no arrojó diferencias relevantes en las creencias de las y los participantes desde las variables referidas.

\section{Creencias docentes sobre la sexualidad, el sexo y el género}

Se evidenciaron tres creencias docentes predominantes en este apartado, que responden a un enfoque conservador: (i) La sexualidad es principalmente biológica, (ii) sexo y el género son lo mismo, y (iii) la homosexualidad es anormal. También, se identificó una creencia docente, en aparente contraposición

166 I con el sistema de creencias predominante de este apartado por responder a un 
enfoque más integral: (iv) es importante el respeto a personas con orientación sexual distinta a la heterosexual.

La primera creencia - "la sexualidad es principalmente biológica" - parte de considerar que el sexo con el que se nace define aquellas conductas y acciones esperadas desde la perspectiva binaria mujer/hombre. Lo señalado se fundamenta en que, aunque se asume que la sexualidad implica comportamientos, estos solo son "comportamientos que pertenecen a lo que es, qué te digo, el de ser mujer o ser hombre" (Profesora 5, Cívica). En ese sentido, aunque los docentes logren entender la sexualidad como parte de la identidad, lo hacen desde el binario biologicista: "[La sexualidad es] saberse identificar como hombre o como mujer” (Profesora 6, Religión).

Esta creencia docente también repercute en cómo conciben el género. En algunos casos, lo diferencian del sexo, pero la separación es difusa. El grupo de docentes entrevistados considera que el género define y diferencia tangencialmente a hombres y mujeres a través de modos de actuar esperados.

Desde que tengo uso de razón; la primaria, a mí me enseñaron género masculino o femenino $i n o$ ? [...] yo no veo la diferencia, masculino o femenino $[\ldots]$ sexo es la parte sexual [...] Y género, tanto femenino como masculino. O sea, la masculinidad, la voz gruesa, el corte. Que no es igual en una señorita que es más delicada, más fina. (Profesor 3, Educación para el Trabajo)

La cita anterior también evidencia la potencia de aquellas creencias docentes construidas desde la formación temprana en consonancia con su retroalimentación en la sociedad (Clark y Peterson,1986, citados en Richards, Gallo y Renandya, 2001) y su permanencia a lo largo del tiempo (Pajares, 1992). Lo señalado se refleja cuando el Profesor 3 (Educación para el trabajo) brinda su definición sobre el concepto de género a través de una vinculación entre su educación escolar y la forma en la que entiende el término en la actualidad.

La segunda creencia docente - aquella que equipara el sexo con el género- se sustenta en el binarismo sexo/género que plantea lo biológico como natural, inmodificable y polarizado (Plaza, 2015). En este marco, la dimensión cultural es anulada: "[El género] es reconocer el varón que tiene que ser varón y la mujer que tiene que ser, porque acá solo hay dos sexos [...]. El tema social no tiene que ver acá" (Profesora 6, Religión). Aquella posibilidad de expresión fuera de lo natural, hombre/mujer o masculino/femenino, no es aceptada.

No podemos hablar de género sin hablar de sexo, ¿no? Es lo mismo. El hombre viene con su género masculino, viene con su sexo [...]. No se debe tratar de hacer lo contrario, porque no me parece ético. No me parece, ¿no? Estaría en contra de la moral y las buenas costumbres ese tipo de querer hacer. (Profesor 2, Matemáticas) 
Una de las consecuencias de entender a la sexualidad y al género como dependientes del sexo biológico es la reproducción de estereotipos de género. Por ejemplo, desde esta perspectiva, se percibe al hombre como más sexual que la mujer: "Son más los varones que las mujeres [los que se masturban]" (Profesor 1, Matemática). Asimismo, se le atribuye características y comportamientos asociados con la fuerza: "Vemos que la fuerza del hombre con el de la mujer es muy diferente" (Profesor 2, Matemática). En contraposición, la mujer es asociada con un rol sumiso y se asume que tiene menor curiosidad sexual: "Se da el caso de que las alumnas, hoy en día, este, esperan que, en cuanto al enamoramiento, ¿no? Esperan que los chicos son los que [las] buscan a ellas" (Profesora 5, Cívica).

También, se identificó una narrativa que confunde al género con la orientación sexual, como se observa en la siguiente cita: "la inclinación de género que tengan; masculino o femenino [...] en el caso se vea que tenga más una inclinación o una tendencia homosexual" (Profesor 3, Educación para el Trabajo). Aunque la estructura oracional dificulte comprender la cita, lo que este docente refirió era que el género era lo mismo que la orientación sexual, esta última denominada - por el docente-como "inclinación" o "tendencia".

En la tercera creencia docente identificada, la homosexualidad es entendida como anormal. Dicha creencia se evidencia a través de narrativas que consideran lo no heteronormado - en particular, la homosexualidad - como una enfermedad contagiosa, lo cual se observa en los siguientes comentarios:

La homosexualidad tanto de hombre, de mujer es una enfermedad [...] siempre ha existido, pero qué pasa, ahora, ahora es escandaloso [...]. Hacen sus cosas que, a la vista y paciencia de jóvenes, de niños, de adultos, ¿no? Y eso también genera que, a veces, el niño mira, ¿no? Ve eso, y dice, ¿no?: "Bueno, si él lo hace por qué yo no lo puedo hacer". (Profesor 2 Matemática)

Sin ser homofóbica diré que no es algo normal, ¿no? Este, que hable como un caso normal, ¿no? Que se hable de homosexualidad, sí, porque es una realidad [...]. Creo que sí debemos dar a conocer esto de la homosexualidad que se da [...]. Acá es un poco infeccioso el sida [...]. Yo creo que, hoy en día, pues, las niñas que están con adolescentes de acá, del mismo distrito, pues ellos [los estudiantes] por una zapatilla, por un..., por tonterías, de verdad, cosas así, superficiales, tienen, llegan a estar con homosexuales. (Profesora 5, Cívica)

En el discurso de la Profesora 5 (Cívica), se refuerza la naturalización de lo heterosexual, mientras que se asocia la homosexualidad con lo anormal. No obstante, ella considera que se debe hablar del tema porque, aunque es negativa, es una realidad. Los prejuicios identificados con respecto a la relación directa entre el sida, la prostitución y la homosexualidad reproducen uno de los 
estigmas más enraizados contra las personas homosexuales (Rentería, 2017), que reducen su existencia a la marginalización. Los límites de este estudio no permiten contrastar el discurso de la docente con la realidad del contexto donde desempeña su práctica pedagógica; sin embargo, el atribuir este tipo de problemáticas a los homosexuales, de manera directa, permitiría concluir que este cúmulo de prejuicios forma parte de las creencias de la docente en relación con la homosexualidad (Rodríguez, 2018). Es interesante analizar este aspecto, dado que las y los estudiantes se encuentran inmersos en medio de una diversidad de creencias sobre la sexualidad y el género que, ante una falta de formación en educación sexual, puede generar que se vean influenciados por las creencias de sus docentes.

Como se mencionó al inicio de esta sección, se identificó una cuarta creencia, según la cual se debe respetar a aquellas personas con una orientación sexual distinta a la heterosexual. Esta parte de una narrativa sobre el respeto a las personas y se ubica en aparente contraposición a las tres creencias docentes predominantes identificadas en este estudio, dado que responde a un enfoque más integral. Dicha narrativa se manifestó en el discurso aparentemente contradictorio de la Profesora 5 (Cívica), quien señaló que una persona no es homofóbica, aunque piense que la homosexualidad es anormal. Desde esta perspectiva, se sugería que lo anormal no responde a lo no común, sino a una forma inadecuada de ser. Una contradicción similar se observa en el discurso del Profesor 2 (Matemática), quien señaló que la homosexualidad "es una enfermedad" y, a su vez, afirmó: "no creo que, porque tengan inclinaciones, homosexual, o gay, o lesbiana, se les falte el respeto".

Esta aparente contraposición responde a la estructura psicológica de los sistemas de creencias que no necesariamente cumplen con criterios lógicos (Guerra, 2013), lo que posibilita la existencia de nociones opuestas, que conviven en el sistema intramental de cada docente. No obstante, las creencias predominantes, producto de la socialización temprana de los individuos (Ernest, 2005), son aquellas que tendrán un mayor impacto en el moldeamiento de la práctica pedagógica docente. Por tanto, al parecer, las creencias negativas sobre la homosexualidad tendrían un mayor peso al formar parte del sistema de creencias docente predominante.

En contraste a todo lo expuesto, el Profesor 1 (Matemática) se presenta como un contraejemplo de lo reportado. Aunque las limitaciones de la presente investigación no permiten analizar las causalidades de la conformación de las creencias del docente en cuestión, podemos suponer que su experiencia de vida pudo influir en el enfoque, en apariencia, más integral que muestra en su discurso. Este docente elabora una definición integral de la sexualidad diferenciándola claramente del sexo. Añade la dimensión emocional y evita que la sexualidad sea reducida a las relaciones sexuales: "La sexualidad que no simplemente es la vida sexual, sino también la vida emocional [...]. Sexo es algo simple, sencillo, biológico, un tanto físico. En cambio, el otro [la sexualidad] ya tiene que ver más con [lo] emocional, sentimental, psicológico". 
Aunque sugiere que los hombres son más sexuales que las mujeres y confunde la definición de género con la de orientación sexual, esboza una definición del primero cercana a su implicancia dentro del proceso de formación de identidad de las personas: "[Género] tiene que ver mucho con lo que llamas, con su vida, con su identidad, con su forma de llevar su vida sexual, ¿no? De su pensamiento psicológico, no sé. El que haya masculino, femenino y homosexuales" (Profesor 1, Matemática). En contraste con los discursos referidos previamente, no considera que la homosexualidad sea negativa. Más bien, visibiliza la diversidad sexual:

Yo puedo biológicamente ser hombre, pero mi vida sexual puede ser la de un homosexual. Yo creo que eso no me quita ni más, ni menos ser persona $[\ldots]$ personas que tienen una orientación sexual, de repente, distinta de nosotros, y eso no significa que sean personas extraterrestres. (Profesor 1, Matemática)

\section{Creencias docentes sobre la educación sexual y las formas adecuadas de impartirla}

Si bien en primera instancia se identificó la creencia docente de que era necesario hablar de educación sexual en el aula - lo cual respondería a un enfoque en apariencia más integral-, en segunda instancia, se observaron dos creencias docentes predominantes sobre educación sexual y las formas adecuadas de impartirla que parecen responder a un enfoque más conservador. De acuerdo con estas últimas, la educación sexual se debe abordar en el aula de manera superficial y la vivencia de la sexualidad adolescente es negativa.

Para empezar, la totalidad de docentes participantes creen en la necesidad de hablar sobre educación sexual en el aula. Resaltaron que también es preciso hacerlo en el hogar: "La educación sexual, para mí, es un tema que se debería abordar tanto en los padres de familia como en el colegio" (Profesora 4, Comunicación). Este hallazgo es significativo, puesto que refuerza los resultados de una investigación sobre educación sexual en Perú, que señala que entre el $97 \%$ y el $100 \%$ de estudiantes, docentes y directores consideran que se debería enseñar educación sexual en la escuela (Motta et al., 2017). En ese sentido, podría servir como fundamento en contra de posiciones que señalan que la plana docente no quiere abordar estos temas y, basándose en ello, refuerzan la idea de que la educación sexual no debe ser abordada en las aulas.

Asociada a esta creencia docente, se considera que las y los estudiantes no cuentan con suficiente información sobre educación sexual en casa. De hecho, el grupo de docentes percibía la existencia de tabúes que impedía a sus alumnos hablar sobre educación sexual en un ambiente de confianza en casa, como se expresa en el siguiente comentario. 
[La educación es importante] Para apoyar a los padres, ¿no? Y porque, siempre los alumnos, hoy en día hay más tabúes con los papás; y, como que siempre sienten más confianza con los profesores. (Profesora 5, Cívica)

Sin embargo, este hallazgo positivo, podría verse limitado por las dos creencias docentes predominantes de esta categoría, las cuales evidencian cómo las personas entrevistadas creen que se debe abordar la educación sexual en el aula.

Por un lado, se identifica la creencia de que la educación sexual se debe abordar superficialmente en el aula. A partir de esta, se revela una contradicción entre lo que se considera que es el deber formativo de la escuela sobre la educación sexual, ante las falencias presentes en el entorno familiar, y la orientación de su práctica pedagógica al abordar el tema. Por ejemplo, el Profesor 1 (Matemática) señala que "hay formas [de abordar la Educación Sexual] sin llegar a, digamos [...] incomodar a los padres". Estas formas se fundan, aparentemente, en el miedo a la respuesta del entorno familiar de sus estudiantes cuando se abordan estas temáticas.

Aunque la identificación de este aparente temor parte del análisis del discurso docente, el contexto de cada entrevista durante el desarrollo de la presente investigación - situado social y culturalmente- podría llevarnos a afirmar que tiene también un correlato con la realidad dado el clima controversial adjudicado al enfoque de género y a la educación sexual en Perú. Este temor se relaciona con dos temáticas específicas: hablar sobre homosexualidad en el aula y hablar de sexualidad de forma explícita, sobre todo, del acto coital. Más adelante, se especifica cómo lo referido se vincula con las propias creencias docentes identificadas en la categoría anterior sobre la sexualidad, el sexo y el género.

Con respecto a la primera temática, se debe anotar que el grupo de docentes entrevistado considera que un tema posiblemente susceptible para las familias es hablar sobre homosexualidad en las aulas - narrativa que se potencia en la creencia de que la homosexualidad es anormal-. Lo referido se evidenció al describir su práctica pedagógica cuando se abordaba la discusión sobre la homosexualidad en el aula; de hecho, persiste la visión negativa de la homosexualidad, sobre todo, si es masculina. Así, aludiendo a un incidente entre dos alumnos, el docente señaló: "Sería una pena [...] que alguno de ustedes [estudiantes varones] [...] se incline a la parte homosexual" (Profesor 2, Matemática).

En las entrevistas, también surgió que el temor ante la respuesta que podría haber en el entorno familiar de los estudiantes si se abordara estos tópicos los lleva a evitar el tema en las aulas: "Hay que tener mucho tino, porque algunos padres vayan a pensar ¿no?: "Ah, está fomentando que mi hijo sea maricón»" (Profesor 1, Matemática). Incluso, en algunos casos, pareciera que la discusión giraba en torno a qué tanto se puede "homosexualizar" a las y los 
estudiantes cuando se aborda el tema. Así, por ejemplo, aunque el Profesor 2 indica que "Hablar de homosexualidad en clase no me parece que tendría a que [los alumnos] se vuelvan homosexuales", se contradice en otro momento. Esto ocurre cuando al describir un incidente en clase, en que un alumno molestaba por una supuesta homosexualidad, menciona:

Yo lo miro y lo llamo al joven, le digo [...]: "Por favor, no vuelvas [a molestar a tu compañero con ser homosexual]; al contrario, hazlo, convérsale, háblale, que él se incluya" [...]. No trates de inducirlo a que, de repente, pueda cambiar de opción". (Profesor 2, Matemática)

Aunque el Profesor 2 inició reafirmando la imposibilidad de que por "exposición" una persona se "vuelva" homosexual, al situarse en un caso concreto y elaborar sobre este, expresa la creencia de que las personas pueden ser "inducidas" por otras a una orientación sexual determinada. De este modo, se visibiliza que, si bien es cierto que las y los docentes fundamentan su accionar pedagógico en el temor por la respuesta del entorno familiar, las razones para limitar el abordaje de temas como la homosexualidad también pueden derivarse de sus propias creencias.

Una dinámica similar se observa en el caso de la segunda temática: las y los docentes temen la reacción de las familias si es que se aborda el tema de la sexualidad de manera explícita. Existe un imaginario desde el cual consideran que tratar dicho tema llevará a sus estudiantes a tener relaciones sexuales a temprana edad: "De repente, le parece mal [al padre o madre de familia] que le esté hablando [sobre Educación Sexual] porque dirá, ¿no?: «No, es muy chico, muy pequeño [...] Le estaría motivando a otras cosas [...] de repente, que haga una práctica [sexual]»" (Profesor 2, Matemática). El grupo de docentes, también, percibe que, para las familias, el hablar sobre relaciones sexuales llevará a que las alumnas queden embarazadas:

Casos donde profesoras han hablado [sobre sexualidad] [...]. Y, justo, posteriormente, años después, esta niñita salió embarazada, ¿no? Que, por qué estaba incentivándola-la profesora, una colega - la sexualidad. (Profesora 5, Cívica)

Resalta que el discurso sobre las consecuencias negativas del embarazo adolescente solo se haya dirigido a alumnas, en tanto refuerza el posicionamiento de la mujer como aquella que debe saber contenerse y contener al hombre; en caso contrario, será calificada de manera negativa. Ello se relaciona con los estereotipos reportados en la categoría anterior, en que se identificó la creencia de que el hombre es más sexualizado que la mujer y de que esta debe frenar los impulsos de los hombres: "[La educación sexual debe] abordar también mucho, el enamoramiento y qué es lo que se debe permitir y no permitir 172 I [...]. Yo les digo cada vez: «el hombre llega hasta donde nosotras lo permiti- 
mos»" (Profesora 5, Cívica). Este último discurso podría evidenciar un trato diferenciado y jerárquico entre hombres y mujeres cuando se aborda el tema de la sexualidad en el aula.

Por otro lado, las entrevistas evidenciaron la creencia de que la vivencia de la sexualidad adolescente es negativa, sobre todo, en lo referente al acto coital. Se identificó esta creencia docente en los discursos que sostienen que la educación sexual debe hablar de forma negativa de la actividad sexual o, en todo caso, evitar mencionarla.

El tema es de informarle para que estén prevenidos, para que ellos puedan, digamos, con responsabilidad, cuando tengan su pareja, ¿no? Digamos, este, saber, ¿no? ¿Cuáles son las consecuencias? [...] Hacerles entender que el inicio a temprana edad de las relaciones sexuales lo único que le va a traer es malas consecuencias. (Profesor 2, Matemática)

Sexualidad no es referencia al sexo. El sexo es una cosa y la sexualidad es otra, ¿no? Para aclarar. Para conocer las características básicas de cada género. Y eso sí se puede tocar en clase, pero hablar de relaciones sexuales creo que no. (Profesora 4, Comunicación)

Estos comentarios reflejan, en primer lugar, un modelo de riesgo para abordar la educación sexual, que limita la actividad sexual adolescente a sus consecuencias negativas (AESS et al., 2012). En segundo lugar, manifiestan un modelo moralista, fundamentado en una visión tabú de relaciones sexuales dentro del currículo de educación sexual (Plaza, 2015). Basándose en estos, se promueve enfoques biológicos, en los que solo se informa sobre cambios físicos y hormonales de la sexualidad (Unesci, 2014): "el propósito fundamental de la educación sexual es que los estudiantes se conozcan a sí mismos, se conozcan sus características que tiene el varón y la mujer [...], características físicas y características biológicas" (Profesora 4, Comunicación).

Un caso interesante es el de la profesora de Religión, quien -bajo un modelo de educación sexual moralista (AEES et al., 2012) - señala que el único método seguro es la abstinencia, basándose en el fundamento católico de la virginidad: "Dicen: «profesora, yo no voy a esperar hasta el matrimonio» [...]. Yo les digo [...], desde el punto de vista cristiano, yo te digo que has cometido un pecado mortal" (Profesora 6, Religión). El valor virginal reproduce y refuerza el sistema de creencias patriarcales imperantes en la sociedad. En este sistema, continúa la negación de la sexualidad de la mujer y, si aparece, es condenada. Incluso, esto llega a ser excusa para dudar de su palabra ante un posible abuso sexual.

Una madre de familia bastante preocupada me dice: "Saliendo del colegio, las alumnas vienen, le buscan a mi hijo; mi hijo es mayor de edad. Yo no estoy en casa, he salido", me dice. "Ha pasado de todo y ahora está que lo están denunciando a él". Entonces, por eso, le digo, como que ya 
se está perdiendo, porque en el momento en que te vas a buscar alguien y vas con otra intención es porque ya sabe lo que va a pasar. (Profesora 6, Religión)

Cabe anotar que el Profesor 1 (Matemática) mostró una visión distinta a lo reportado sobre la educación sexual. Aunque comparte el mismo temor ante la respuesta del entorno familiar al abordar el tema y una aparente visión de los hombres como individuos con más sexualidad que las mujeres, la descripción de sus prácticas pedagógicas dan cuenta del desarrollo de un modelo más cercano al integral (AEES et al., 2012). Este docente parece percibir la sexualidad como un hecho natural y no negativo, que se presenta a lo largo del desarrollo de la adolescencia:

La curiosidad [sexual] ya lo tienen; es propia de su edad [...]. [Sobre la educación sexual] intercambiar ideas para que ellos puedan aclarar muchas dudas de todo lo que es sexualidad [...]. La educación sexual ayuda mucho, ¿no? Ayuda mucho a darle la información necesaria para que ellos, como en algún momento, en alguno de los casos, dice que vayan postergando su inicio de su vida sexual. Y, si no la pueden postergar, bueno, que haya un cuidado. (Profesor 1, Matemática)

\section{Creencias docentes sobre el enfoque de género en la educación y lo propuesto por el Minedu}

En este caso, se identificaron dos creencias docentes predominantes sobre el enfoque de género propuesto por el Minedu: (i) que este busca homosexualizar a las y los estudiantes, y (ii) que se limita a hablar de la orientación sexual. En paralelo, se observó una idea que contrastaba con las anteriores: la importancia de la igualdad de oportunidades entre mujeres y hombres.

La primera creencia docente se evidencia en los discursos que buscan describir los planteamientos del Ministerio: "[El Minedu] quiere tocar un tema [el enfoque de género] que no va a resultar. Que va a confundir, más que todo. Imagínate si los papás a veces no lo tocan en casa. Nosotros hablarles y despertarles algo, no me parece" (Profesora 4, Comunicación). Para esta docente, introducir el enfoque de género en clase podría despertar una orientación sexual distinta a la heteronormada, lo cual es preferible evitar. Esta narrativa se relaciona con los hallazgos identificados en la categoría de creencia docente sobre la sexualidad, el sexo y el género, entre los cuales se destacó la percepción de la homosexualidad como un comportamiento anormal.

De manera similar a lo comentado en el apartado anterior, una de las docentes mostró cierto temor frente a la respuesta del entorno familiar si se abordara el enfoque de género. En la narrativa elaborada por esta entrevistada, este enfoque es una imposición de modelos extranjeros que no toma en cuenta la realidad del país. Esta percepción se resguarda en una aparente aceptación 
personal del conservadurismo de la sociedad peruana - que refiere, en este caso, a la no aceptación de la diversidad sexual-, que podría llevar al grupo de docentes a temer la reacción de las familias si se trabaja el enfoque de género en el aula. En este caso, podríamos vincular el aparente temor externo por la respuesta del entorno familiar con las propias creencias de la docente.

El enfoque de género, lo que el Minedu está planteando de alguna manera y, es por eso que los padres salieron a protestar en eso, no te metas con mi hijo, que salieron. Igual los padres, porque, yo creo que el Minedu lo que quiere es ahondar en el tema de homosexualidad, bisexualidad y temas de transgénero. [...] No estamos en un país liberal; todavía estamos en un país bastante cerrado [...]. Esto quizás se pueda aplicar en otros países que están bien desarrollados. [...] [El Ministerio] No ha hecho diagnóstico en cuanto a los niños, a la gente de Perú. Y, quiere tocar un tema que no va a resultar. (Profesora 4, Comunicación)

En este comentario, se menciona de forma directa al colectivo CMHNTM y se alude a la sensación de temor sobre el abordaje del enfoque de género en las aulas por parte del entorno familiar de las y los estudiantes. El hecho de que se aluda directamente a este colectivo nos permite señalar, nuevamente, lo verídico de esta percepción docente en medio del clima controversial que la propuesta del enfoque de género tiene en el contexto peruano actual. Ello refuerza lo complejo de la implementación de este tipo de propuestas educativas en medio de un clima convulso desde el cual las y los docentes deben realizar cambios considerables en su práctica pedagógica, así como en su propia identidad como docentes.

La creencia de que el enfoque de género planteado por el Minedu se limita a hablar sobre la orientación sexual en las aulas aparece cuando definen qué entienden por enfoque de género, más allá de lo propuesto por dicho ministerio. Esta creencia docente también se relaciona con los hallazgos identificados en la categoría sobre la sexualidad, el sexo y el género. Por un lado, persiste la confusión entre el género y la orientación sexual - reportada con anterioridad- al momento de intentar definir el enfoque de género, como se observa a continuación:

[El enfoque de género se refiere] A la opción de género, ¿no? Va inclinado, según a lo que he escuchado, a la homosexualidad, para dar más rienda suelta a esto, ¿ ¿no? Y, si el joven, desea esa opción, optar por eso, pues como que le da más libertad a ello. (Profesora 5, Cívica)

Por otro lado, como posible consecuencia de la creencia docente central que equipara el sexo y el género como si fueran lo mismo, un docente entiende el enfoque de género como herramienta para consolidar las diferencias entre hombres y mujeres. Esto, según Bourdieu (2007 [1998]), ejemplificaría la biologización de lo social a través de la reproducción de estereotipos de género, los que se reflejan en el siguiente comentario: 
El enfoque de género que se debería dar en la educación es, este, consolidar - ¿no? - claramente las diferencias que hay entre un género y otro. Y que, digamos, este, hacer entender a los educandos, ¿no?, que están a nuestro cargo de que hay el varón y la dama. [...] Haciendo deporte se podría ver ese enfoque. [...] Digamos, el vóley lo juegan tanto el hombre como la mujer. Pero también vemos que la fuerza del hombre con el de la mujer es muy diferente ¿no? y el físico. (Profesor 2, Matemática).

En contraposición a estas dos creencias docentes predominantes, la mayoría de docentes plantearon una tercera, según la cual es importante la igualdad de oportunidades para hombres y mujeres. Así, reportaron que sería adecuado que el enfoque de género adoptado por el Minedu se oriente en función de ello. Este discurso que promueve la equidad entre hombres y mujeres resulta interesante, en tanto refleja un enfoque binario inclusivo.

Si realmente ese enfoque que ellos han propuesto es para que las posibilidades de darle a la mujer y al hombre sean las mismas, está bien [...] porque la ley nos dice, ¿no?, que tanto el hombre como la mujer tenemos los mismos derechos. (Profesor 2, Matemática)

No obstante, la aceptación de las identidades de género distintas a las heteronormadas es más difícil de asumir, puesto que no respaldan la estructura de creencias docentes identificada. Este último hallazgo es importante por dos motivos. Primero, las y los docentes no asocian el fomento de la igualdad entre hombres y mujeres con el enfoque de género propuesto por el Minedu (2016), a pesar de que sí está planteado en él. Parece ser que la campaña masiva de colectivos en su contra, aunado a la desinformación sobre esta propuesta, repercute en cómo las y los docentes entienden el enfoque de género. Solo la mitad de los entrevistados señalaron que estaban informados sobre el enfoque de género $y$, lo que es aún más relevante, ninguno reportó algún tipo de acompañamiento por parte del Minedu. Segundo, pese a que el sistema de creencias que tienen el grupo de docentes sobre el enfoque de género propuesto por el Minedu es negativo, se identificó esta creencia docente final que establece un posible puente de diálogo para poder implementar el enfoque de género en la educación.

\section{Conclusiones}

El objetivo general de esta investigación fue explorar las creencias docentes sobre el enfoque de género y la educación sexual. Los resultados permitieron identificar un sistema de creencias predominante con un claro enfoque conservador en torno a la sexualidad, el sexo y el género. Este influye significativamente en cómo cada docente cree que deben impartir ambos enfoques a través de su práctica pedagógica. Este sistema consta de tres creencias docentes predominantes que-bajo una lógica binaria, heteronormada y estereotipada- 
sitúan a la sexualidad como principalmente biológica; homologan al sexo y al género; y consideran que la homosexualidad es anormal. Dicho sistema concuerda con lo que Ortiz-Hernández (2004) propone como las tres ideologías que sustentan y reproducen un sistema patriarcal: el heterosexismo, el apego a los estereotipos de género y el antropocentrismo propulsor de la supremacía masculina (Pecho, 2017).

En sintonía con la literatura revisada, este sistema predominante parece privilegiar aquellas creencias nucleares formadas durante la etapa de formación educativa de las y los docentes (Clark y Peterson, 1986, citados en Richards, Gallo y Renandya, 2001), y aquellas sujetas al sistema de creencias compartido por la sociedad (Ernst, 1989). En tal sentido, consideramos plausible que, tanto en el contexto educativo como en el social, la construcción temprana de estas creencias docentes podría explicarse a partir de su socialización en un sistema que se contrapone con el enfoque de género y la educación sexual.

Ello se podría ver reflejado en el sistema patriarcal imperante en la sociedad peruana, como también en el discurso de desprestigio sobre el enfoque de género por parte de los colectivos ultraconservadores como CMHNTM, que tienen una gran influencia en el debate actual sobre estas temáticas. En ese marco, es pertinente señalar que las y los docentes que participaron de esta investigación comparten el complejo imaginario social del contexto peruano, construido en torno a las temáticas de género y sexualidad, lo cual no es un hallazgo aislado, ni gratuito, ni únicamente presente en el discurso de la plana docente.

Asimismo, el sistema de creencias docentes predominante identificado parece propiciar la reproducción de modelos de riesgo y moralistas para abordar la educación sexual. Este resultado dialoga con investigaciones previas que identificaron la reproducción de este tipo de modelos de educación, tanto a nivel regional (Quaresma da Silva, 2012; Plaza, 2015) como a nivel internacional (Díaz de Greñu y Anguita, 2017; Preston, 2013). Los hallazgos del presente estudio también podrían mostrar que ambos modelos limitan un abordaje profundo de la educación sexual en las escuelas. Por un lado, y acorde a investigaciones previas (Preston, 2013; Quaresma da Silva, 2012), ambos promueven la persistencia de una visión restringida y de riesgo sobre la sexualidad, que se traduce en la reproducción de prácticas correctivas y regulatorias. Por otro lado, parecen promover representaciones hegemónicas y estereotipadas sobre lo masculino/femenino ${ }^{2}$ y sobre la orientación sexual.

Además, este sistema de creencias docentes predominante parece materializarse en una visión negativa del enfoque de género en la educación, que surge desde un discurso estereotipado sobre el género y una visión negativa de la homosexualidad. Investigaciones previas sobre el tema han planteado este hallazgo (Quaresma da Silva, 2012; Plaza, 2015; Díaz de Greñu y Anguita, 2017).

2. Esto es sugerido en investigaciones previas (Garrahy, 2001; Quaresma de Silva, 2012; Plaza, 2015; Díaz de Greñu y Anguita, 2017). 
No obstante, es importante señalar que las creencias docentes predominantes sobre el enfoque de género también responden a una falta de acompañamiento por parte del Minedu sobre lo propuesto en el Currículo Nacional del 2016; de hecho, ningún docente reportó recibir acompañamiento en la materia por parte de esta entidad. Así, aunadas al clima de desinformación sobre la propuesta institucional, conviven creencias docentes estereotipadas, que llevan a los profesores a considerar que esta propuesta es negativa, debido a que busca homosexualizar a sus estudiantes y solo se limita a abordar la orientación sexual.

A partir de ello, se evidencia la necesidad de que, junto con las políticas educativas que favorezcan la inclusión del enfoque de género y la educación sexual en el currículum escolar, se establezcan mecanismos institucionales que permitan que esta propuesta tenga una repercusión real en la práctica pedagógica y, en consecuencia, en la enseñanza de las y los estudiantes. En esa línea, esta investigación destaca la relevancia de la institucionalización de procesos de acompañamiento docente en la materia. Dichos procesos deberían permitir, a través de una práctica reflexiva, hacer explícitas estas creencias, y dialogar en torno a ellas y a las experiencias que las han construido, como un medio para facilitar la dificultad de la implementación del enfoque de género y la educación sexual en el sistema escolar peruano.

Los hallazgos también evidenciaron un contraejemplo, a partir del caso del Profesor 1 (Matemática), así como tres creencias docentes que se contraponen y, a la vez, conviven con el sistema reportado: (i) el respeto a las personas con orientación sexual distinta a la heteronormada, (ii) la necesidad de hablar sobre educación sexual en el aula, y (iii) y la relevancia de promover la igualdad de oportunidades entre hombres y mujeres. El contraejemplo parece presentar una visión más integral de la sexualidad, y un discurso de respeto e inclusión de la diversidad sexual. Ello se ve reflejado en los modos en que describe su práctica pedagógica al abordar la educación sexual, más cercana a un modelo integral y a una visión positiva sobre el enfoque de género. Así, se reforzaría la postura teórica que afirma la influencia de las creencias sobre la práctica pedagógica (Pajares, 1992).

Por su parte, se identificó la presencia de tres creencias docentes que responden a un enfoque más integral antes que conservador, lo que indicaría una aparente contraposición respecto al sistema de creencias predominante del grupo de docentes entrevistado. Lo referido se podría explicar desde la naturaleza psicológica de los sistemas de creencias, que señalan que estas no necesariamente cumplen con criterios lógicos (Guerra, 2013); por tanto, pueden parecer contrapuestas y, a la vez, coexistir con el sistema de creencias docentes reportado. Es preciso enfatizar que aquellas creencias más profundas suelen tener un mayor peso en el accionar de las personas. No obstante, su identificación nos invita a validar y reflexionar su existencia dentro el sistema de creencias docentes sobre la educación sexual y el enfoque de género en la educación.

Estas creencias son un punto de partida importante para el diálogo en 178 I torno a estas temáticas, y posibilita la creación de planteamientos para abordar 
la tarea titánica de la inclusión del enfoque de género y la educación sexual en la escuela secundaria peruana desde la perspectiva docente. Dichos planteamientos deben valorar sustancialmente los hallazgos positivos de esta investigación, por ejemplo, la valoración positiva que muestran los entrevistados hacia la equidad por género.

Concluimos, de forma general, que el sistema de creencias docentes predominante identificado sustituye el conocimiento explícito (Catalán, 2011), contenido en la propuesta institucional del Minedu. Cabe anotar que la intención educativa primordial de esta última es promover un modelo de educación sexual integral y una educación con enfoque de género. Los resultados de este estudio se alinean con investigaciones latinoamericanas afines y, además, permiten entender la dificultad actual para la implementación de la propuesta del Minedu desde la perspectiva docente.

En realidad, estos resultados no debieran sorprendernos si consideramos el contexto patriarcal, discriminador, y reticente - tanto en creencias como en prácticas - al enfoque de género y a la educación sexual en el que todas y todos (incluidos los docentes) habitamos. A ello se debe añadir que, pese a que ha habido esfuerzos desde el Minedu para formular estas temáticas a nivel curricular, tampoco se ha diseñado un acompañamiento a las y los docentes para su implementación, y - mucho menos- sobre lo que este implica para ellos como personas que tienen experiencias, creencias y posturas en torno al tema. Siendo la sexualidad y el género temas tan ligados con la propia identidad, tan cargados de afectos y tan poco dialogados en nuestra sociedad, no tendríamos por qué asumir que no demandan un acompañamiento especial para que sean trabajados en la escuela. Esto es aún más importante en el contexto de un debate muy convulsionado y por momentos enardecido sobre la propuesta que el Minedu busca implementar. La tarea es, sin duda, colosal y en esta coyuntura las y los docentes recurren, desde las mejores intenciones, a aquello que creen adecuado para acompañar a sus estudiantes. En ese sentido, una educación sexual y con enfoque de género demandaría, como primer paso, el poder trabajar con la plana docente, atendiendo a la diversidad y complejidad de creencias que detentan, de modo que puedan construirse espacios de reflexión conjunta que les permita poder tener herramientas para abordar el tema.

Esta investigación, de forma general, destaca la potencia de las creencias docentes para influir y moldear el accionar pedagógico, las cuales se configuran como un constructo que ayudaría a comprender la práctica pedagógica dentro del aula (Pajares, 1992) sobre estas temáticas. No obstante, se trata de un estudio de carácter exploratorio, dada su naturaleza cualitativa, su alcance limitado a las y los participantes, y debido a que el campo de creencias docentes en nuestro país y su estudio desde la Psicología Educativa recién empieza a generar aportes en torno a temas vinculados a la educación sexual y al enfoque de género.

Los hallazgos de la presente investigación brindan como aporte fundamental el prestar especial atención a las creencias docentes referidas a la 
sexualidad, el sexo y el género al plantear programas de acompañamiento docente referidos a la educación sexual y al enfoque de género. Asimismo, sugiere prestar especial atención a aquellos puntos de encuentro que existen entre el pensamiento docente y la propuesta institucional. En el contexto de esta investigación, estos se vieron evidenciados en las tres creencias que coexisten con el sistema de creencias docentes identificado. Esta acotación podría configurar el punto de partida para un cambio-desde la propia perspectiva docenteque promueva cambios significativos y no una lista de conceptos nuevos que adquirir.

La naturaleza epistemológica de la presente investigación no permite la generalización de los datos recogido; no es esa su finalidad. No obstante, nos lleva a reflexionar sobre la relevancia de abrir un campo de investigación desde la Psicología de la Educación orientado a explorar cómo, desde la perspectiva docente, podemos mejorar las prácticas educativas en lo que respecta a las temáticas de género y sexualidad en las escuelas. Esta reflexión debe tomar como base una visión positiva de las y los docentes, que invite a co-construir nuevos aprendizajes, y nuevos modos de entender y entenderse a partir del género y la sexualidad. Asimismo, nos invita a considerar e investigar los procesos de formación inicial de futuras y futuros docentes. Problematizar y debatir sobre qué tipo de competencias debemos desarrollar en estos espacios de formación profesional docente es un deber y un medio pertinente para aminorar la dificultad de la implementación de estas temáticas en la práctica docente.

Las limitaciones de la presente investigación no permitieron identificar ni analizar los procesos de construcción de las creencias docentes identificadas en este estudio. Desde una perspectiva psicológica, sería pertinente abordar este tema a través del estudio de la construcción de la identidad docente, específicamente profundizando en sus posicionamientos con respecto al enfoque de género y a la educación sexual. Tampoco, fue posible analizar cómo las creencias docentes reportadas se manifiestan concretamente en el aula de clases, aspecto que convendría explorar mediante observaciones o grabaciones. Otra limitación refiere a que no ha sido posible realizar un análisis de la información en función de las variables de sexo y género, lo cual sería pertinente considerar en futuras investigaciones. También, sería interesante explorar cómo y bajo qué mecanismos se podría materializar un cambio de creencias docentes que promuevan la concreción de las intenciones educativas, alineadas con una educación sexual integral y con enfoque de género. Para ello, sería pertinente emplear métodos de investigación en la práctica que posibiliten identificar aquellos mecanismos o principios que podrían favorecer la implementación de programas docentes, ya sea formativos o de acompañamiento. 


\section{Referencias bibliográficas}

Abenoza, R. (1994). Sexualidad y juventud. Guía práctica para monitores/as. Madrid: El Popular S.A.

Aller, L. M. (1995). Pedagogía de la sexualidad humana. Buenos Aires: Galerna.

American Psychological Association [APA] (2011). Respuestas a sus preguntas sobre las personas trans, la identidad de género y la expresión de género (Brouchure de la APA Lesbian, Gay, Bisexual and Trasgender Concerns Office y de la APA Public and Member Communicationes). Recuperado de: http://www.apa.org/topics/lgbt/brochure-personas-trans.pdf

Asociación Española de Especialistas en Sexología, Academia Española de Sexología y Medicina Sexual, Asociación Mundial para la Salud Sexual, Federación Latinoamericana de Sociedades de Sexología, Programa Modular de Salud Sexual de la Universidad Nacional de Educación a Distancia y el Instituto Espill de Sexología, Psicología y Medicina (2012). Educación para la sexualidad con bases científicas. Documento de Consenso de Madrid. Recuperado en http://www.flasses.net/boletines/educacion_ para_la_sexualidad.pdf

Bank, B. (2007). Gender and education: An encyclopedia. Vols I y II. Londres: Praeger.

Bardi, A., Leyton, C., Martinez, V. y Gonzáles, E. (2005). Identidad sexual: Proceso de definición en la adolescencia. Reflexiones Pedagógicas, 43-51.

Borg, M (2001). Teacher's beliefs. English Language Teachers Journal, 55(2), 186-188.

Bourdieu, P. (2007 [1998]). La dominación masculina. Barcelona: Editorial Anagrama.

Braun, V. y Clarke, V. (2006). Using thematic analysis in psychology. Qualitative research in psychology, 3(2), 77-101.

Calderhead, J. (1996). Teachers: Beliefs and knowledge. En D. Berliner y R. Calfee (Eds.), Handbook of Educational Psychology (pp. 709-725). New York: Macmillan.

Callejo, M. y Vila, A. (2003). Origen y formación de creencias sobre la resolución de problemas. Estudio de un grupo de alumnos que comienzan la educación secundaria. Boletín de la Asociación Matemática Venezolana, 10(2), 225-247.

Catalán, J. (2011). Del pensamiento al conocimiento profesional del profesor. En J. Catalán y J. Redondo (Eds.), Psicología educacional. Proponiendo rumbos, problemáticas y aportaciones (pp. 187-216). La Serena: Editorial Universidad La serena.

Con Mis Hijos No Te Metas Perú-Oficial (CMHNTM) (2016, 15 de diciembre). Respuesta al mensaje de la nación del presidente Pedro Pablo Kuczynski 
[Archivo de video]. Recuperado de https://www.facebook.com/ ConMisHijosNoTeMetasOficial/videos/344217052618886/

Corte Suprema de Justicia de la República. Expediente N 23822-2017-Lima, Corte Suprema de Justicia de la Republica, 2019.

Creswell, J., Hanson, W., Clark, V. y Morales, A. (2007). Qualitative research designs: Selection and implementation. The Counseling Psychologist, 35(2), 236-264.

Díaz de Greñu, S. y Anguita, R. (2017). Estereotipos del profesorado en torno al género y a la orientación sexual. Revista Electrónica Interuniversitaria de Formación del Profesorado, 20(1), 219-232.

Dirección de Tutoría y Orientación Educativa [Ditoe] (2008). Lineamientos educativos y orientaciones pedagógicas para la educación sexual integral. Recuperado de http://bvs.minsa.gob.pe/local/minsa/1283_GOB523.pdf

formación de docentes en educación sexual integral. Recuperado de http://repositorio.minedu.gob.pe/bitstream/handle/MINEDU/5623/ Propuesta $\% 20$ para $\% 201$ a $\% 20$ formaci $\%$ C $3 \%$ B 3 n $\% 20$ de $\% 20$ docentes\%20en\%20Educaci\%C3\%B3n\%20Sexual\%20Integral. pdf? sequence $=1 \&$ is Allowed $=y$

Dirección de Tutoría y Orientación Educativa [Ditoe] y Organización de las Naciones Unidas para la Ciencia y la Cultura [Unesco] (2013). Educación sexual integral: Derecho humano y contribución a la formación integral. Recuperado de http://unesdoc.unesco.org/images/0022/002217/221729s.pdf

Ernst, P. (1989). The impact of beliefs on the teaching of mathematics. En P. Erns (Ed.), Mathematics Teaching: The State of the Art (pp. 249-254). Londres: Falmer Press. Recuperado de http://socialsciences.exeter.ac.uk/ education/research/centres/stem/publications/pmej/impact.htm

Fondo de Población de las Naciones Unidas [Unfpa] (2005). Antecedentes, situación actual y desafíos de la educación de la sexualidad en América Latina y el Caribe. México, D.F.: Unfpa - Equipo de Apoyo Técnico para América Latina y el Caribe.

Fuster, D. (2019). Investigación cualitativa: Método fenomenológico hermenéutico. Propósitos y Representaciones, 7(1), 201-229. https://dx.doi. org/10.20511/pyr2019.v7n1.267

Garrahy, D. (2001). Three third-grade teacher's gender-related beliefs and behavior. The Elementary School Journal, 102(1), 81-94.

González, F. (2007). Investigación cualitativa y subjetividad: Los procesos de construcción de la información. México, D.F: McGraw-Hill Interamericana.

Guerra, F. (2013). Creencias sobre ciudadanía y educación ciudadana en docentes de un colegio público y un colegio privado de Lima (tesis de licenciatura). Pontificia Universidad Católica del Perú, Lima. Recuperado de http://tesis. 
pucp.edu.pe/repositorio/bitstream/handle/123456789/5081/GUERRA_ RODRIGUEZ_FERNANDO_CIUDADANIA_EDUCACION. pdf? sequence $=1$ \&isAllowed $=y$

Hsieh, H. y Shannon, S. (2005). Three approaches to qualitative content analysis. Qualitative Health Research, 15(9), 1277-1288.

Husserl, E. (1998). Invitación a la fenomenología. Barcelona: Paidós.

Instituto Nacional de Estadística e Informática [INEI]. (2015). Perú: Encuesta demográfica $y$ de salud familiar 2014: Nacional y departamental. Recuperado de https://www.inei.gob.pe/media/MenuRecursivo/ publicaciones_digitales/Est/Lib1211/pdf/Libro.pdf

Kirby D. B. (2008). The impact of abstinence and comprehensive sex and STD/HIV education programs on adolescent sexual behavior. Sexuality Research and Social Policy, 5(3), 18-27.

Lamas, M. (2009). La perspectiva de género. La Tarea: Revista de Educación y Cultura, 8, 5-12.

Marcelo, C. (1987). El pensamiento del profesor. Barcelona: CEAC.

(2005). La investigación sobre el conocimiento de los profesores de aprender a enseñar: Una revisión personal. En G. Perafán y A. AdúrizBravo (Eds.), Pensamiento y conocimiento de los profesores (pp. 47-62). Bogotá: Nomos.

Meinardi, E, Plaza, M. V. y Revel Chion, A. (2010). Educación en ambiente y salud. En E. Meinardi (Ed.), Educar en ciencias (pp. 191-224). Buenos Aires: Paidós.

Ministerio de Educación del Perú [Minedu] (2005). Diseño Curricular Nacional de educación básica regular. Recuperado de http://www.minedu.gob.pe/ normatividad/reglamentos/DisenoCurricularNacional2005FINAL.pdf

(2009). Diseño Curricular Nacional de educación básica regular, Recuperado de http://www.minedu.gob.pe/ normatividad/reglamentos/DisenoCurricularNacional.pdf

(2013). Lineamientos y avances en la implementación de las políticas de educación con enfoque de género. Recuperado de http://www.minedu.gob.pe/comision-sectorial/pdf/foropucp.pdf

(2015). Experiencia de transversalización del enfoque de género en el Ministerio de Educación. Recuperado de http:// www.minedu.gob.pe/comision-sectorial/pdf/comision-13-03-15.pdf (2016). Currículo Nacional de la Educación Básica. Recuperado de http://www.minedu.gob.pe/curriculo/pdf/ curriculo-nacional-2016-2.pdf

(2018, 20 de marzo). Sobre el enfoque de igualdad de género y el currículo nacional de la educación básica 
[Comunicado de prensa]. Recuperado de http://www.minedu.gob.pe/n/ noticia.php?id=46159

Ministerio de la Mujer y Poblaciones Vulnerables [MIMP]. Política Nacional de Igualdad de Género, Decreto Supremo 008 2019, MIMP (2019).

Moreno, M. (2001). El profesor universitario de matemáticas: Estudio de las concepciones y creencias acerca de la enseñanza de las ecuaciones diferenciales. Estudio de casos (tesis doctoral). Universidad Autónoma de Barcelona.

(2005). El pensamiento del profesor. Evolución y estado actual de las investigaciones. En G. Perafán y A. Adúriz- Bravo (Eds.), Pensamiento $y$ conocimiento de los profesores (pp. 63-80). Bogotá: Nomos.

Morgade, G. (2001). Aprender a ser mujer, aprender a ser varón. Buenos Aires: Novedades Educativas.

Motta, A., Keogh, S. C., Prada, E., Núnez-Curto, A., Konda, K., Stillman, M., y Cáceres, C. F. (2017). De la normativa a la práctica: La política de educación sexual y su implementación en el Perú. Lima: Guttmacher Institute y Centro de Investigación Interdisciplinaria en Sexualidad, Sida y Sociedad. Recuperado de https://www.guttmacher.org/sites/default/files/ report_pdf/de-la-normativa-a-la-practica-educacion-sexual-peru.pdf

Organización de las Naciones Unidad para la Educación, la Ciencia y la Cultura [Unesco] (2014). Educación integral de la sexualidad: Conceptos, enfoques $y$ competencias. Recuperado de http://www.unesco.org/new/fileadmin/ MULTIMEDIA /FIELD/Santiago/pdf/Educacion-integral-sexualidadconceptos-enfoques-compete.pdf

(2015). Guía para la igualdad de género en las políticas y prácticas de la formación docente. Recuperado de http://www.unesco. org/fileadmin/MULTIMEDIA/FIELD/Santiago/pdf/guia-igualdad-degenero-formacion-docente.pdf

Ortiz-Hernández, L. (2004). La opresión de minorías sexuales desde la inequidad de género. Política y Cultura, (22), 161-182.

Padres en Acción Perú (2017, 30 de enero). Poder Judicial admite demanda de acción popular contra el Currículum Nacional de Educación Básica [Comunicado de prensa]. Recuperado de https://docs.wixstatic.com/ ugd/732934_be8f1e1d4cbd49d9b513d00324d3b21b.pdf

Pajares, M. (1992). Teacher' beliefs and educational research: Cleaning up a messy construct. Review of Educational Research, 62(3). 307-332.

Pecho, P. (2017). Sexismo ambivalente, pensamientos patriarcales y violencia simbólica intra e inter género en Lima y Huancayo (tesis de titulación). Pontificia Universidad Católica del Perú, Lima. Recuperado de http://tesis. pucp.edu.pe/repositorio/bitstream/handle/123456789/9129/PECHO_ RICALDI_PRISCILLA_SEXISMO_AMBIVALENTE_PESAMIENTOS_ 
PATRIARCALES_Y_VIOLENCIA_SIMBOLICA_INTRA_E_INTER_ GENERO_EN_LIMA_Y_HUANCAYO.pdf? sequence=1 \&isAllowed $=\mathrm{y}$

Plaza, M. (2015). Caracterización de las creencias sobre sexualidad de los profesores y su incidencia en las prácticas sobre educación sexual en la escuela media (tesis doctoral). Universidad de Buenos Aires, Buenos Aires. Recuperado de http://digital.bl.fcen.uba.ar/Download/Tesis/Tesis_5871_ Plaza.pdf

Preston, M. (2013). Very very risky: Sexuality education teacher's definition of sexuality and teaching and learning responsibilities. American Journal of Sexual Education, 8(1/2), 18-35.

Quaresma da Silva, D. (2012). La producción de lo normal y lo anormal: Un estudio sobre creencias de género y sexualidad entre docentes de escuelas municipales de Novo Hamburgo/Brasil. Subjetividady Procesos Cognitivos, 16(1), 178-199.

Rentería, M. (2017). Una aproximación a las tipologías en la investigación sociológica a partir de los estilos de vida de homosexuales masculinos en Lima. Empiria. Revista de Metodología de Ciencias Sociales, 36, 89-117.

Richards, J. C., Gallo, P. B., y Renandya, W. A. (2001). Exploring teachers' beliefs and the processes of change. The PAC Journal, 1(1), 41-62.

Rodríguez, A. (2018). Creencias docentes: El enfoque de género en la educación y la educación sexual en secundaria (tesis de licenciatura). Pontificia Universidad Católica del Perú, Lima. Recuperado de http://tesis.pucp.edu. pe/repositorio/handle/123456789/13039

Rodríguez, J. (2014). La reproducción en la adolescencia y sus desigualdades en América Latina: Introducción al análisis demográfico, con énfasis en el uso de microdatos censales de la ronda de 2010. Santiago de Chile: Naciones Unidas. Recuperado de http://dev.consultorsalud.org/sites/ consultorsalud/files/informe_cepal_0.pdf

Uccelli, F., Agüero, J., Pease, M. y Portugal, T. (2017). Atravesar el silencio: Memorias sobre el conflicto armado interno y su tratamiento en la escuela. Lima: Tarea Asociación Gráfica Educativa.

Underhill K., Montgomery, P. y Operario, D. (2007). Sexual abstinence only programmes to prevent HIV infection in high income countries: Systematic review. British Medical Journal, 1-12. Recuperado de https:// www.bmj.com/content/bmj/335/7613/248.full.pdf

Vásquez, V. (2015). Modelo teórico de la estructura y dinámica de las identidades sexuales (tesis de titulación). Universidad Nacional Mayor de San Marcos, Lima. Recuperado de http://cybertesis.unmsm.edu.pe/bitstream/handle/ cybertesis/4442/Vasquez_mv.pdf?sequence $=1$

Vieytes, R. (2004). Metodología de la investigación en organizaciones, mercado $y$ sociedad. Buenos Aires: Editorial de las Ciencias. 
Vygotsky, L. (2000 [1978]). El desarrollo de los procesos psicológicos superiores. En M. Cole, V. John-Steiner, S. Scribner y E. Souberman (Eds. y Trad.), Lev Vygotsky: El desarrollo de los procesos psicológicos superiores. $3^{\circ}$ Ed. Barcelona: Crítica. 